\title{
The sedimentary record of dinoflagellate cysts: looking back into the future of phytoplankton blooms*
}

\author{
BARRIE DALE \\ Department of Geology, University of Oslo, PB 1047 Blindern, N-0316 Oslo, Norway.
}

\begin{abstract}
SUMMARY: Marine systems are not as well understood as terrestrial systems, and there is still a great need for more primary observations, in the tradition of the old-time naturalists, before newer methods such as molecular genetics and modeling can be fully utilized. The scientific process whereby the smaller, detailed "building blocks" of observation are ultimately linked towards better understanding natural systems is illustrated from my own career experience, especially with regard to the dinoflagellates and plankton blooms. Some dinoflagellates produce a fossilizable resting stage (cyst) in their life cycle, and dinoflagellate cysts have become one of the most important groups of microfossils used in geological exploration (e.g. oil and gas). This has stimulated both paleontological and biological research producing detailed "building blocks" of information, currently scattered throughout the respective literature. Here, I attempt to bring together the present day perspective, from biology, with the past, from paleontology, as the most comprehensive basis for future work on the group. This shows the cysts to be the critical link needed for focusing future molecular genetics studies towards a more verifiable view of evolutionary pathways, and it also suggests new integrated methods for studying past, present, and future blooms. The large, rapidly growing field of harmful algal bloom studies is producing many different "building blocks", but plankton blooms as episodic phenomena are still poorly understood. This is largely due to the general lack of long-term datasets allowing identification of the changing environmental factors that permit certain species to bloom at unpredictable intervals of time. Cysts in sediments are useful environmental indicators today, e.g. reflecting aspects of climate and pollution, and provide information directly relevant to some dinoflagellate blooms. They therefore may be used for obtaining retrospective information from the sedimentary record on the history of blooms, in turn suggesting information relevant for future blooms and the way we study them.
\end{abstract}

Key words: dinoflagellate cysts, algal blooms, eutrophication, molecular genetics, paleoceanography, transfer functions.

"you are the best qualified person I know of .......not on the supposition of [your] being a finished naturalist, but as amply qualified for collecting, observing \& noting anything new to be noted in Natural History."

Letter from J.S. Henslow, 24 August 1831, to Charles Darwin, recommending him as naturalist to the Beagle voyage.

"I believe there exists, and I feel within me, an instinct for truth, or knowledge or discovery, of

*Received August 3, 2001. Accepted August 16, 2001. something of the same nature as the instinct of virtue."

A later letter from Charles Darwin to his by then old friend J.S. Henslow.

\section{PREAMBLE}

I feel a heavy burden of responsibility, having accepted the invitation to join "a group of senior scientific sages" charged with the task of "transmitting a career's worth of wisdom and knowledge to young sages-to-be". This is not lightened by the fact that it 
is to be achieved through "candid, honest and open dialogue", at the EMBS Meeting and in this written contribution. However, I can liken my own early career to hitch-hiking, where the "drivers" of that time were very generous to me as I sat by the roads of science waving my thumb. It is therefore with a deep sense of gratitude to former colleagues, at the Geology Department, Sheffield University, and the Woods Hole Oceanographic Institution, that I can now offer this contribution "from the driving seat".

Geologists generally enjoy synthesizing information from the past, and the main part of this presentation will attempt to pass on at least some knowledge from my own (continuing!) career. Deciding what might be relevant wisdom for today's young sages-to-be, is harder. The intellectual challenge embodied in Darwin's words quoted above still represents the main driving force for many of us trying to understand more of the natural world, but increasingly this is perceived as too unrealistic for the modern world, where scientific research is in danger of being absorbed into society's paid beaurocracy as a service industry. One of my favorite sages, the late Holger Jannasch (1997), commenting on the waste caused by funding pressures, wrote: "The effect is worse on younger scientists, who are not rewarded for tackling a problem with perseverance, but for hopping from one promising or prioritized subject to another; funding, not science, being the ultimate goal". I hope young scientists are wise enough to balance these destructive pressures with the basic joy of science which Holger stated later in the same article: "My critical remarks notwithstanding, I am, as most of my colleagues are, well aware of the privilege of being paid for work that often feels like the pursuit of a hobby".

One further point that I wish to address, regarding the way we approach basic research, concerns the need to specialize. Especially within educational circles, the need to produce more generalists in science, i.e. people with more than a one discipline view, is often stated. Ironically, my own experience strongly suggests that one of the most effective ways to achieve this, at least in marine science, is by dedicated specialization. Marine systems are still poorly understood (certainly compared to terrestrial systems), and marine science therefore still needs the combination of sample collecting and primary observation that Darwin enjoyed 150 years ago. Contributing the necessary primary observations today demands more specialization, but this may still be carried out in the best traditions of naturalists such as
Darwin: curious enough, determined enough, and not least willing to ignore the boundaries between the various natural sciences. Some of the best things happen in marine science, as in natural science in general, by examining some smaller entity in great detail and relating this to a bigger picture. Applying the naturalist approach, it is virtually impossible to delve deep enough to make a significant specialized contribution without being confronted by the need to understand other overlapping fields.

Young sages-to-be may well consider this concept, too, to be unrealistic for the modern world. It is certainly difficult to compare the hectic, heavily managed framework for basic research today with visions of Darwin sailing round the world for years, studying all aspects of natural history. A would-beDarwin, today, would have difficulty funding a project with a main objective to concentrate on geological observations, and a secondary objective to contemplate (for a few years) the morphological details of certain finches, and the possible implications of this for creation. Nevertheless, the inquisitive, observant and interdisciplinary approach of the early naturalists still offers the best way of tackling the enormous task of primary observations needed to understand marine systems.

This poses problems for today's scientist. Firstly, it may be difficult to accept that part (much?) of marine science is still at the basic level of observation, whereas the rest of science is already testing paradigms and modeling systems. From this perspective, it is certainly not prudent to cite old sages such as Darwin in the methods section of research proposals. Even those scientists who recognize the basic value of interdisciplinary research may experience difficulty in accepting responsibility for this in practice. Having studied the small entity in great detail, many may feel that it is sufficient to publish this in a specialized journal with minimum discussion of its implications for the bigger picture (safe science). Indeed, this view is rewarded by the career system in academia, which often seems to give more weight to the frequency, and possibly the volume of publications rather than to their scientific depth.

In my own career, I have been privileged to be able to follow a somewhat unusual course that has allowed me to wander freely between aspects of geology, biology and oceanography. Inevitably, this has required spending proportionally more time reading than writing compared with a more conventional, single discipline approach; for example, based on following the literature in any one of my 
main fields of interest (micropaleontology, plankton biology, harmful algal blooms, eutrophication and marine pollution). Therefore, it might seem negligent for me to recommend that any younger scientist should attempt to follow such a multidisciplinary path today, even though I have argued strongly for the need. However, despite the problems noted above, I remain an optimist by nature, and two reasons prompt me to appeal for a return to a more naturalist approach.

The first, and probably by far most important reason, concerns the seemingly unlimited opportunities opened up by modern communication. Basic information for "the other overlapping fields of research" is far more easily available through electronic networks today, and there is a continuous stream of data being collected from satellites and well-equipped ships. This, together with opportunities for various specialists to cooperate in multidisciplinary research projects, or informal networking groups, should provide exciting opportunities for modern scientists to carry on the work started by the old-time naturalists. The second reason concerns the sort of efforts being made through this meeting. The hope here is that senior scientific sages can help draw together some of the otherwise more isolated details, and place them in a larger perspective that somehow improves the way we see things now, and helps shape the way we do our science in future.

I will attempt to do this, here, based on my own career's experience. The main theme concerns the phytoplankton of the oceans, appropriate for a celebration of Professor Margalef, and the large part of his scientific life devoted to unraveling the complexity of their ecology, certainly in the best traditions of natural history.

\section{INTRODUCTION}

My own career began in geology in the early1960s; helping to develop techniques for extracting some of the wealth of fascinating microfossils found in the geological record. It is now taken for granted that the microfossils provide the main evidence for organic evolution through more than the first three-quarters of the history of life on Earth (e.g. Brasier, 1980), but having seen some of these for the first time has always felt like a privilege. Almost nothing was known regarding their biological affinities, and the next phase in my work involved a move to oceanography, helping to iden- tify the affinities of a previously unknown group, the hystrichospheres, that were promising to be particularly useful in geology. We proved these to be the resting stages (cysts) of dinoflagellates by incubating living representatives of the group (e.g. Wall and Dale, 1966, 1968; Fig. 1). It is not possible to describe the exciting sense of discovery we experienced, linking these "living fossils" with their biology. For us, this was like finding some unknown egg in a remote desert, today, and incubating it to hatch out a real-life dinosaur (the first cyst we incubated belongs to a genus, Spiniferites, dating back to the time of the dinosaurs). That one of the major groups of microfossils proved to represent a stage in the life cycle of one of the major groups of phytoplankton, opened up new perspectives, and consequently, most of my work since has focussed both on the biology and paleontology of dinoflagellates.

A lot of work has been done on dinoflagellates in the past twenty years, mostly by specialists either in micropaleontology or plankton biology. The fossil cysts have been developed as one of the main groups used routinely in biostratigraphy (e.g. in the oil and gas industry; Stover et al., 1996). This, in turn, has stimulated research on living cysts, particularly distribution studies aimed at testing their potential value as paleoenvironmental indicators (e.g. Dale, 1996). Biological studies of dinoflagellates have largely been stimulated by the increasing focus on harmful algal blooms (HABs). Dinoflagellates are one of the main groups causing HABs, and there is increased awareness of the possible role of cysts as seed beds and toxin sinks. From my paleo-biological perspective, I see areas where the knowledge developed within the one discipline is relevant to developments in the other, and therefore should influence it more. Hence, this attempt to build bridges between the two.

As the title suggests, I shall first use the paleopart of this perspective to look back into the cyst record in sediments, and identify information of particular relevance to better understanding dinoflagellate biology. The second part of the title relates this to future biological work on the group, most of which is likely to be directed towards understanding blooms. Understandably, much of the basic biological information to date is influenced by chance, (e.g. dependent on which species is available for study in laboratory cultures). The aim, here, is to identify from the cyst record fundamental problems needing to be understood, so that 

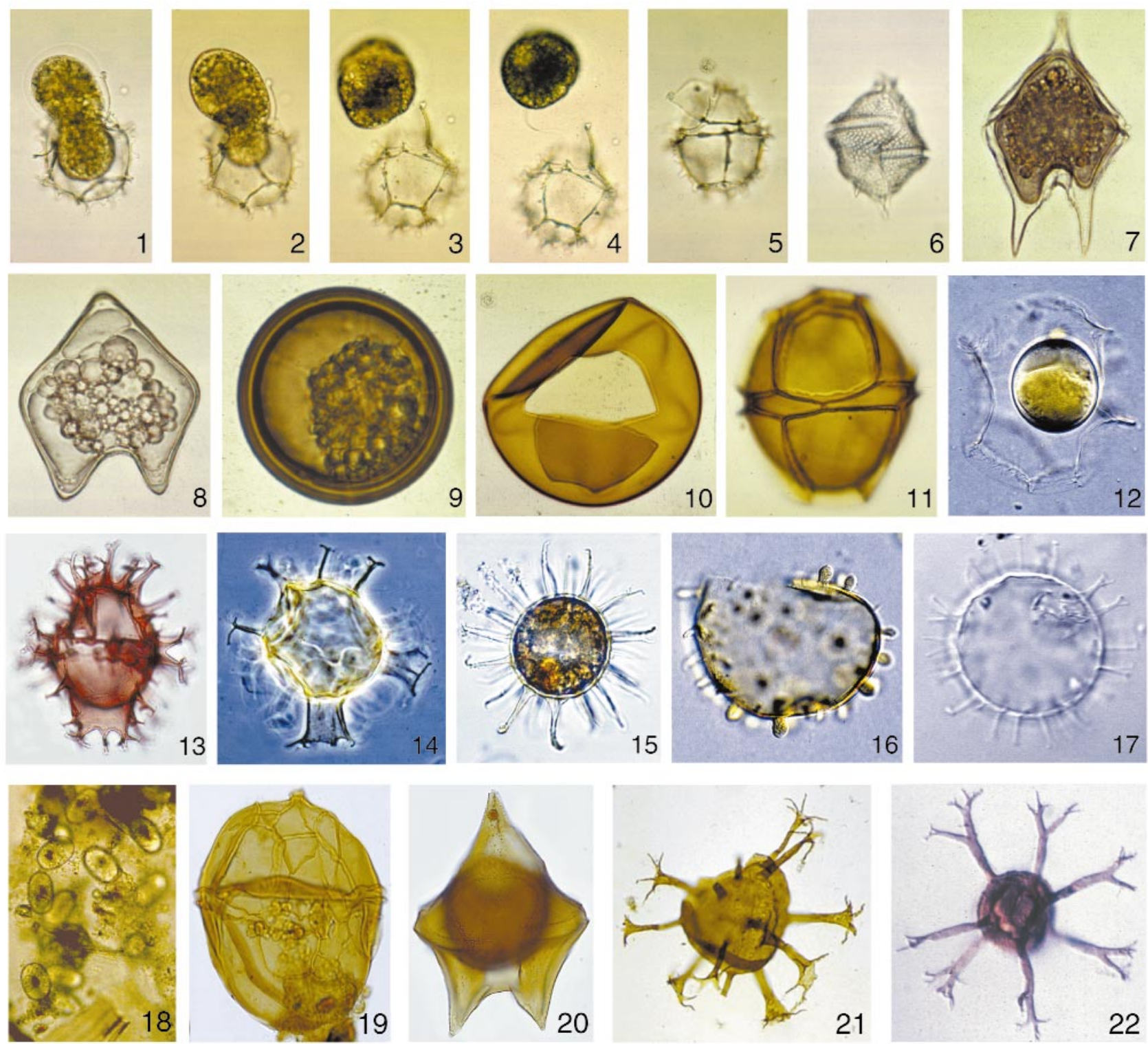

FIG. 1. - Dinoflagellate cysts - ancient and modern.1-6. One of the first documented excystment series from a dinoflagellate cyst ( Gonyaulax digitalis incubated from local bottom sediment in Woods Hole Harbor, reported by Wall and Dale, 1968: Fig. 2). The prevalvate "gymnodinioid" stage with only one functional flagellum emerged through the archeopyle within just a few minutes (note the gelatinous cover surrounding the protoplast as it emerged by amoeboid movement). 5. Empty cyst remaining after excystment, referable to the paleontologically named cyst Spiniferites bentori (this genus has a fossil record extending back to the Cretaceous). 6 . The theca developed by the emerged motile stage after one day; identified as G. digitalis to establish the theca/cyst relationship linking plankton biology and paleontology of the group. 7. Encystment of Protoperidinium oblongum (newly formed cyst inside the theca of the planozygote); Woods Hole plankton, september,1965. 8. Resting phase in Protoperidinium oblongum cyst, showing lipid globules presumably serving as food reserves; bottom sediment, Woods Hole, 1965. 9. Resting cyst of Protoperidinium conicoides; bottom sediment, Woods Hole, 1965. 10. Large round brown protoperidiniod cyst showing archeopyle and partially attached operculum; recent sediment off the coast of Peru. 11. Impagidinium patulum, a warm-water oceanic indicator, with reflected plate pattern; recent sediment, Mediterranean Sea. 12. Impagidinium pallidum, an extremely cold-water oceanic indicator, bipolar; deep-sea sediment trap sample, Fram Straight, N.E. North Atlantic. 13. Spiniferites mirabilis, a cosmopolitan coastal species; recent sediment, Norway. 14. Spiniferites membranaceum, a colder-water coastal species; recent sediment, Norway. 15. Gonyaulax polyedra (= Lingulodinium machaerophorum), cyst in resting phase, a warmer-water coastal species; recent sediment, Los Angeles Harbor, USA. 16. G. polyedra cyst showing reduced, bulbous processes characteristic for low salinity waters (e.g. compare processes with those in 15); recent sediment, Baltic Sea. 17. Peridinium faeroense (= Pentapharsodinium dalei) cyst, a living acritarch produced by a thecate dinoflagellate; recent sediment, Norway (photo by M.L.L. Sætre). 18. Low magnification view of rich concentration of living cysts of the toxic Alexandrium tamarensis, potential seed beds and sinks for large amounts of toxin; deeper water recent sediment, offshore Gulf of Maine, USA. 19-21. Fossil dinoflagellate cysts (photos by R.L. Williams). 19. Leptodinium mirabile, a cyst showing almost complete reflected plate pattern of a dinoflagellate; Jurassic sediment (ca. 155 million years old), Svalbard. 20. Deflandrea phosphoritica, cyst showing some obvious morphologic relationship to the dinoflagellates; Eocene sediment (ca. 50 million years old), Texas, USA. 21. Oligosphaeridium sp., cyst showing less obvious morphologic relationship to the dinoflagellates (apical archeopyle, and each process representing reflection of a plate in the recognizable "thecal" pattern); Cretaceous sediment (ca. 135 million years old), Svalbard. 22. A Paleozoic acritarch showing no obvious morphologic relationship to dinoflagellates, but the rich assemblages of such acritarchs, predating the recognized cyst record, most likely include some earlier dinoflagellate cysts (photo by G.D. Wood). 
future biological studies can help be more focussed toward these. Biology provides a present-day perspective, paleontology the past, and together they should offer the most comprehensive basis for future work.

This short contribution will concentrate more on concepts and ideas; minimum space is used for repeating documentation from the often more specialized literature, but this is covered through a few key references pointing to further reading.

\section{Dinoflagellate cysts}

Dinoflagellates are one of the major groups of microplankton, present in virtually all aquatic environments, where they often account for substantial amounts of the planktic biomass (e.g. Taylor, 1987). Approximately half of the known species are photoautotrophs, and the group was traditionally considered to be part of the phytoplankton, classified within the algae. In fact, they are an ancient, highly complex group, including many heterotrophic species living by predation on other microplankton, and some mixotrophic species combining both trophic methods. They are single-celled, and are now considered to be protists, classified within their own Division, Dinoflagellata (Fensome et al., 1993). Prior to the 1960s, they were studied almost exclusively from the characteristically biflagellated motile cells found regularly in the plankton, and the morphology of this stage still largely forms the basis for classification.

The discovery, by paleontologists in the 1960s, of a resting cyst in the life cycles of many species was surprising to plankton biologists (Dale, 1983). A review of the earlier plankton literature shows occasional observations of what we now know to be cysts, but neither the extent nor the significance of this had been realized before. Approximately 10\% of the around 2000 marine species of dinoflagellates produce such cysts, and they are widely considered to be formed as hypnozygotes in a sexual cycle. Most of them appear to serve as a benthic resting stage: cell contents full of food-storage products such as starch grains and lipids, enclosed in a protective cell wall, and equipped with a mandatory resting period. The cell wall in many species comprises heavy, complex organic molecules (dinosporin), similar to the sporopollenin of plant spores and pollen grains; others produce thick cyst walls of calcite crystals, and even a few siliceous cysts are known from the fossil record. They are extremely resistant to physical, chemical, and bio- logical breakdown; some have remained viable for up to ten years in anoxic black mud in my refrigerator, while a few reports elsewhere suggest the possibility for survival over at least several tens of years. The empty non-mineralized cyst walls show various degrees of resistance. In many species these are resistant enough to fossilize, whereas others do not seem to persist from surface sediments into the fossil record, and some degrade within a few minutes of excystment.

Little is known regarding why and how cysts form in nature. Cyst-formation has been induced in laboratory cultures of some species by exposing them to nutrient starvation, and this has lead to the widespread concept of cysts forming in response to adverse conditions. However, in general it is hard to correlate the regular, yearly, cyst formation in the natural environment (e.g. in a Norwegian fjord) with adverse conditions. On the contrary, the little available evidence suggests that cyst formation may be associated with maximum population numbers of motile cells (presumably maximizing the chances for successful mating), with no demonstrated lack of nutrients. The inducement of excystment in laboratory experiments is more compatible with observations from nature, at least for temperate to high latitude environments. After completion of dormancy, cysts will excyst if returned to an appropriate temperature for the motiles to grow. This presumably provides a basis for the cysts to function as an overwintering stage at higher latitudes, but offers no plausible explanation for how the many cyst-forming species function at equatorial to low latitudes. At these latitudes, some species, including the HABproducing Gymnodinium catenatum, may in fact produce cysts that excyst normally within a few days without accumulating as potential seed beds (Dale and Amorim, 2000).

It should be obvious, even from this very brief summary, that we still know little concerning the basic biology of the cysts. However, a review of the current literature shows an increasing awareness within plankton biology of the need to better understand resting stages in general, and dinoflagellate cysts in particular. I am therefore confident that biologists will continue the research needed to find out more about what the cysts are, and why and how they function in the life cycle. I will try to draw together some points of interest from the fossil record that may help formulate research strategies for increasing the worth of such research to both biology and paleontology. 
THE SEDIMENTARY RECORD OF DINOFLAGELLATE CYSTS: WHAT'S IN IT FOR BIOLOGY?

It is convenient to consider the record of cysts in sediments on different time scales, as seen by looking back: 1) over the past few years to tens of years represented by recent sediments - allowing us to relate cyst distributions to known environmental parameters, and assess their potential as environmental indicators; 2) tens to hundreds of years in short cores - useful for assessing human impact; 3) thousands to a few millions of years in longer cores or rock sequences - e.g. useful for detecting effects of major climatic change; and 4) hundreds of millions of years in rocks - necessary for tracing pathways of evolution.

\section{The past few years time scale: cysts as environmental indicators}

Both paleontologists and plankton biologists may be surprised by the extent to which cysts in recent sediments reflect their environments. Planktic organisms such as dinoflagellates, easily dispersed from their ecological core regions by water transport, are not usually considered likely to be useful environmental indicators. The standard biogeographic zones in the ocean are therefore defined largely using benthic organisms or others such as fish, able to actively maintain contact with a definable environment. Nevertheless, the first studies on distribution of cysts in recent (surface) sediments showed this to be closely linked to environment (e.g. Wall et al., 1977), and some cyst types are now considered to occupy some of the main biogeographic zones previously established from the benthos, etc. (Dale, 1983, 1996). Some other cysts show biogeographic distributions closely corresponding to those of macro algae. This is presumed to reflect a life cycle in the cyst-forming dinoflagellates incorporating both a planktic phase and a benthic phase (cyst) that effectively "anchors" the species to a preferred environment, e.g. somewhat comparable to mollusks or attached algae, also with planktic life cycle stages.

This research has begun to suggest an ecological classification for the cyst types, but in order to establish, and apply, such a classification also requires understanding the sedimentary system. The organicwalled cysts behave as fine silt particles in the sedimentary regime, and tend to be transported and accumulated with this fraction. In cyst distribution studies, it is therefore critical to distinguish between more sheltered coastal waters, with minimal sediment transport, and more exposed offshore waters with possibilities for long distance transport. Many cysts seem to be produced by species living in coastal and neritic waters (not surprising if they are reliant on completing a life cycle with a benthic resting stage). It is studies of these cysts in sheltered bays, fjords, and boat basins along coasts that is revealing consistent biogeographic zones; however, these coastal cysts may be regularly transported further offshore, and eventually dispersed into the deep sea, far outside their ecologically critical core areas. Some investigations (notably those employing transfer functions), discussed below, fail to recognize this, and treat even the cyst assemblages in the deep ocean as representative of surface water conditions immediately overlying sediments in water depths of up to several $\mathrm{km}$.

Recent cyst distributions described so far allow basic ecological classification into the following main categories (summarized in Dale, 1996): cosmopolitan species (equatorial to sub-polar in both hemispheres); cold-water coastal species (polar to sub-polar, mostly bipolar); warm-water coastal species (equatorial to temperate); warm-water oceanic species (a few truly pelagic species with cysts functioning in some alternative way to benthic resting stages); and cold-water oceanic species (one so far described, the bipolar Impagidinium pallidum, occupying extremely cold, oceanic, polar waters). Combinations of these cyst assemblages, in turn, allow the identification of ecological signals (i.e. recognition from the cysts of certain environmental parameters) potentially useful for paleoenvironmental interpretations. To date, these (summarized in Dale, 1996) include cyst signals of: sea-water temperature, salinity, coastal versus oceanic waters, and productivity (e.g. oceanic upwelling, and coastal eutrophication).

\section{The tens to hundreds of years time scale: cysts as indicators of human impact on the environment}

The natural sciences are being challenged by public concern over impact on the marine environment of a rapidly growing human population, and associated industrialization. All too often, this requires scientists to provide assessments of changes over time in environments where the necessary long 
term monitoring data is inadequate. Micropaleontology is helping by providing retrospective data from microfossils archived in bottom sediments, and the first attempts to apply dinoflagellate cysts in this way are summarized by B. Dale and A.L. Dale (in press). The cyst record shows significant (often considerable) changes in assemblage composition on the scale of tens to hundreds of years. This should be of interest to plankton biologists, since there are very few consistent long term plankton datasets, even within the range of tens of years, offering a framework for assessing their many short term observations.

Some of the noted shifts in cyst assemblages may be related to climatic change (discussed in the next section), but others are associated with marine pollution, particularly cultural eutrophication. One cyst signal of cultural eutrophication was described from the Oslofjord (Dale et al., 1999), based on comparing changes in the cyst record in cored sediments (dated by lead isotopes) with the known history of cultural eutrophication. The main elements of this signal are illustrated in Figure 2, and comprise: 1) overall increased cyst concentration (approximately a doubling of numbers of cysts/g dry sediment) -interpreted as reflecting increased productivity, including the cyst-forming dinoflagellates; and 2) a massive increase of the photoautotrophic species Gonyaulax polyedra (= Lingulodinium polyedrum)that blooms in the fjord in late summer. This species is thought to have benefited particularly from the nutrients added throughout the year from sewage; the fjord is an otherwise nutrient-limited system in which the spring bloom utilizes much of the available nutrients, and summer-blooming species are restricted to what is remaining. The extra nutrients presumably did not stimulate growth in the spring plankton, since this was not previously limited by nutrients; an assumption supported by the fact that a prominent spring-blooming species, Peridinium faeroense (=Pentapharsodinium dalei) showed no increase (Fig. 2).

A very different cyst signal has been obtained from the several examples studied so far of systems presumed not to have been nutrient-limited prior to pollution. However, since the published examples are from sites subjected to both sewage effluent and heavy industrial pollution, this makes it impossible to separate (identify) possible effects of eutrophication from possible effects of the industrial pollution (e.g. in the Frierfjord, Norway, by Sætre et al., 1997; and in Tokyo Bay, Japan, by Matsuoka, 1999; discussed by Dale, 2001). Nevertheless, ongoing analyses by Sætre of several Norwegian fjords not affect-

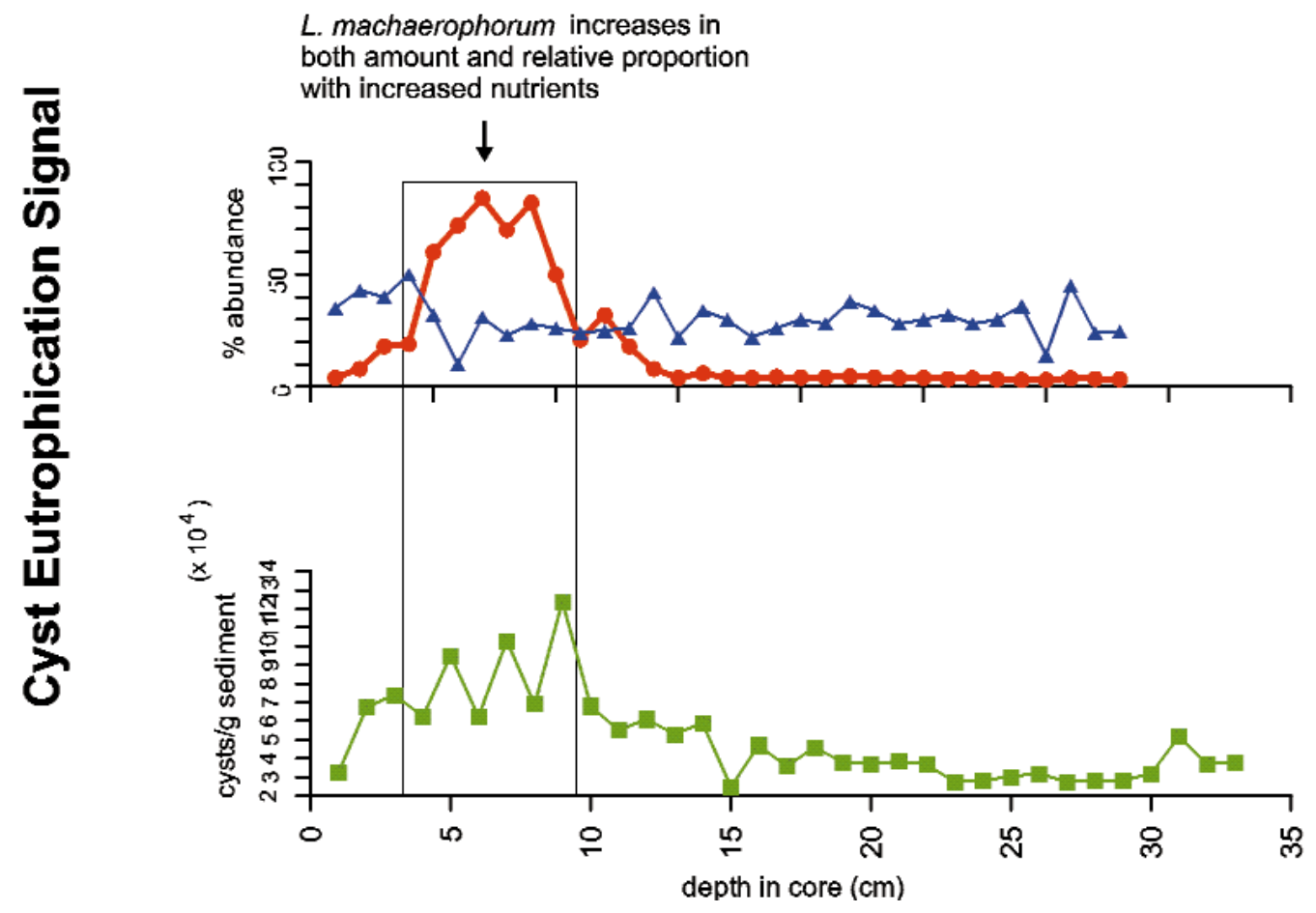

FIG. 2. - Diagramatic representation of the cyst eutrophication signal in the inner Oslofjord. Box shows time period with documented eutrophication from about 1900 to 1980 . Note that the spring blooming species Peridinium faeroense (blue triangles) showed no increase during eutrophication 
ed by massive industrial pollution, suggest this to be an alternative signal of eutrophication (Sætre and Dale, 2001, poster at this meeting). This signal is characterized by: 1) unchanged, or reduced cyst concentrations; and 2) at least a marked proportional shift to more heterotrophic species.

\section{The few millions to thousands of years time scale: how were dinoflagellates affected by the Great Ice Ages?}

It is a sobering thought that for many thousands of years prior to about 10,000 years ago, here where I sit writing this in my home near Oslo would have been covered by an approximately $4 \mathrm{~km}$ thick ice sheet. There is a wealth of literature describing how the earth's climate has changed continuously throughout geological time, on many different time scales, and there is evidence of previous massive glaciation as far back as 2.5 billion years ago (BYA). We know that the last Great Ice Age in the northern hemisphere began about 2.5 MYA, whereas ice on Antarctica occurred at least as far back as 40 MYA.

The dramatic effects of the last glaciation on the terrestrial environment are well documented, e.g. fossil pollen showing the migration of vegetational zones such that parts of southern Europe were covered by birch forest and scrub-tundra while Scandinavia was covered by its thickest ice sheet (van der Hammen et al., 1971). Great effort has been made during the past 25 years to generate corresponding information from the oceans. Micropaleontology provides much of the evidence, and of particular interest, here, is the fact that dinoflagellate cysts are proving useful as "marine pollen". The biogeographic zones established for recent cysts (described above), can be seen to migrate in the world's oceans in response to climatic oscillations between glacial and interglacial conditions, on the time scale of many thousands of years, analogous to terrestrial vegetation (Dale, 1996).

Investigations on the time scale of just a few thousand years have even allowed us to identify fossil "blooms" of species seemingly caused by the smaller scale climatic changes typical within what may well be the present interglacial period. In a series of long sediment cores from the KattegatSkagerrak region of Scandinavia, we documented two periods of marked increased abundance ("blooms") of what was then considered the cyst of the toxic species Gymnodinium catenatum, dated to around $6000 \mathrm{yrs}$ BP (before present) and $1000 \mathrm{yrs}$
BP. Subsequent studies confirmed the close association of the later of these with the Medieval Warm Period, and its termination corresponding to the Little Ice Age (e.g. Thorsen and Dale, 1998). This species (now called G. nolleri) is not recorded live from the region today (although present in small numbers further down the Danish coast), but at the height of the Medieval Warm Period, it dominated cyst assemblages by up to around $60 \%$. Its known distribution elsewhere confirms this to be a warmer water species (e.g. living along the Iberian Peninsula, and in Australia). That the estimated average temperature increase of around $1-2^{\circ} \mathrm{C}$ could have caused such an assemblage shift, at least within the cyst-forming species of dinoflagellates, is of interest to both paleontology and biology.

At the other extreme of the time scale under consideration, i.e. tens of millions of years, we may explore some of the effects of major climatic change on the dinoflagellates as a group. Comparing the known geological ranges for the different ecological groups classified through our recent cyst distribution database produced interesting results. Figure 3 shows plots for the geological ranges for twenty of the ecologically most important cysts in our global database, suggesting the following main conclusions: 1) the cosmopolitan, and the warmer water coastal species are both long-ranging, with origins predating the onset of major glaciation at around Middle Miocene time; 2) the warmer oceanic species show similar, though not such long ranges; and 3) the colder water coastal species are short ranging, post dating the onset of major glaciation.

Not surprisingly, the main interpretation of these results suggests that the plankton living at present includes: 1) cosmopolitan species that have survived a long time due to their broad tolerance for environmental change; 2 ) warmer species that were able to survive global cooling by remaining in the albeit reduced warmer zones; and 3) newer cold water species presumably having evolved to occupy the colder waters generated by global cooling.

\section{The hundreds of millions of years time scale: the big picture}

The dinoflagellates have an unusual fossil record, with an isolated occurrence of fossil cysts in the Silurian (about 400 million years ago (MYA)), followed by a gap of around $200 \mathrm{MY}$ before the rich and varied, continuous, record from the Late Triassic to the present. While this record certainly is 


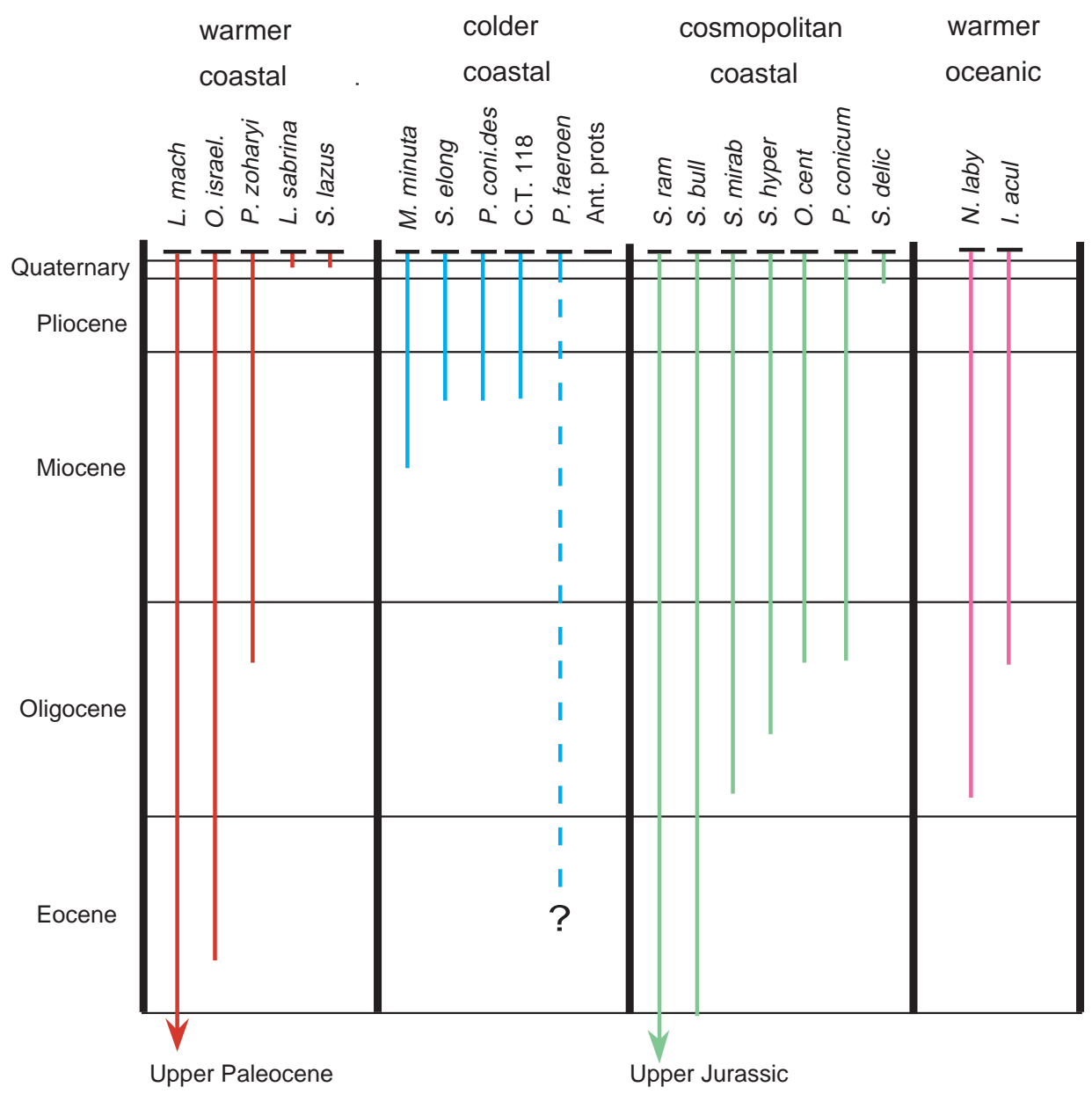

FIG. 3. - Age ranges for twenty of the most ecologically important cyst types in our global database of recent cyst distribution. Ecological groupings for the cysts are defined in the text.

influenced by heavy sampling biases (due largely to where in time and space geologists have explored for oil and gas), the basic pattern including vast amounts of time with no fossil cysts is expected to be representative. There are several reasons why this fossil record should not be taken as the complete picture of dinoflagellate evolution. Organic geochemistry reveals the presence of marker species of compounds (dinosterols) believed to be uniquely produced by dinoflagellates, at least as far back as the Cambrian (Moldowan and Talyzina, 1998), suggesting the presence of the group well before 500 MYA. The seeming conflict between this and the stated fossil record from the cysts may be explained to some extent by the patchy nature of cyst formation and preservation previously outlined. Given that only some species form cysts today, and many of those may not fossilize, maybe the group initially "experimented" with the need for fossilizeable cysts for a long time.
This may have contributed, but a more powerful explanation is to be found through closer examination of the definition of dinoflagellate cysts. As some of the previously unknown hystrichospheres were identified as dinoflagellate cysts, and therefore transferred to that group, a new inserte sedis group, the acritarchs, was erected (Evitt, 1963) to accommodate those remaining. The acritarchs are thus a large group of organic-walled microfossils, of unknown biological affinity, presumed to include representatives from many different biological groups. The dinoflagellates are defined morphologically based on characteristic features of the living motile cells, which do not fossilize, though these diagnostic features may be reflected to some extent in the morphology of cysts, revealing their biological affinities. This is particularly the case in many cysts of thecate dinoflagellates (i.e. those with motile cells covered by series of clearly defined cellulosic plates), where the cyst morphology may reflect at least part of a plate pattern. 
This type of reflected morphology allows dinoflagellate cysts to be identified as such, even from the fossil record (Fig. 1), but it is important to realize that by no means all living cysts show such features, and those that do are almost exclusively from thecate dinoflagellates. Incubation experiments with living cysts have thus confirmed the dinoflagellate affinities of some of the important cyst types prominent in the paleontological record (e.g. the ancient genus Spiniferites). They have also revealed many cysts lacking the reflected features of motile stages, that otherwise would be classified as acritarchs in the fossil record. One acritarch, believed to be the living representative of a species originally described from the Eocene (around 40 MY ago), even incubated to produce a thecate dinoflagellate identified as Peridinium faeroense (Dale, 1978).

This has serious implications for interpreting the fossil record of the group. Whereas some dinoflagellate cysts are identified morphologically to produce the fossil record, it may be assumed that others remain unidentified within the acritarchs. The acritarch record is characterized by a wealth of described species from the Precambrian to the end of the Paleozoic Era (i.e. before the continuous identified cyst record begins) that most likely include the earliest dinoflagellate cysts. The classification boundary between acritarchs and dinoflagellate cysts is thus at best fuzzy. This is because paleontologists working far back in geological time are generally reluctant to describe the morphology of acritarchs using cyst terminology, with the implication that these could be cysts before their accepted geological record (even though similar, but non-motile-stage, features are now known from some living cysts). Many paleontologists working at the other end of the record, e.g. with Quaternary to recent samples, more or less ignore the acritarchs, and regularly describe and record "dinoflagellate cysts" that show no reflected motile-stage features, and therefore qualify in fact as acritarchs.

\section{IMPLICATIONS AND APPLICATIONS FOR BIOLOGY}

I realize that it may be difficult for some marine scientists to share a perspective of organic life on Earth subdivided into dinoflagellate cysts and "others". Even within marine biology there still may be scientists who would question the value, to basic research or applied science, of studying one stage in the life cycle produced by $10 \%$ of one group of microplankton. Fortunately, there is no precedence in basic research for having to answer such doubts: you study cysts, or finches, or moldy bread, etc., first, to observe and document the details, so these can be considered together with all the other "building blocks" to develop wider concepts of how natural systems work. In general, science has to happen before applied science; applications become apparent along the way.

Having touched on some of the detailed "building blocks" from the cyst work so far, we can now consider possible implications and applications which these suggest. The main concern, here, is to draw together information pertinent to biology, but there is an equal and opposite need for information flow the other way, as illustrated by the comments (below) on paleoceanography. This is not a full review of the possibilities, but a personal selection, with emphasis on those directions in which I know marine science is going. The general need for more basic biological information on which species produce cysts, and the role of cysts in life cycles, etc., will not be elaborated further, since both paleontologists and biologists are aware of this, and in some cases working on it. Inevitably, there are recurring themes (e.g. the need for paleontologically relevant cultures), but for convenience, my comments are gathered under the following selected topics: 1) genetics and evolution; 2) paleoceanography; 3) environmental sciences; and 4) blooms.

\section{Genetics and evolution: the ultimate overlap of paleontology and biology}

The application of molecular genetics to problems concerning evolution and phylogeny is one of the most rapidly developing fields of research in biology. It is also one of the most promising lines of future research that should help develop greater understanding of the evolution of the phytoplankton. For the dinoflagellates, this will necessitate more consideration of the cysts: since the fossil record of dinoflagellates is made up of cysts, the living cysts represent the critical link between biological and paleontological information developed for the group so far. With respect to dinoflagellates, the question, here, is not so much what cysts can do for future applications of molecular genetics, but rather how such studies can proceed without them. 
To date, the first attempts to apply these new tools to reconstruct evolutionary pathways for the dinoflagellates have relied heavily on the relatively few available cultures, almost exclusively species with no known cyst record. While these first results seem promising, they hang largely in paleontological limbo. The scientific value of future applications would therefore be strengthened enormously if they could include a selection of cyst-forming species that are as representative as possible of both the main morphological groups of cysts and as wide a span as possible in their geological ranges. This would require close cooperation between paleontologists and geneticists (easy to justify scientifically), and the establishment of paleontologically relevant cultures (long overdue for a wide variety of related studies).

Results such as those discussed above, and shown in Figure 3, support the need for future applications to progress from samples of opportunity to targeted species. While such results may be anticipated from basic principles of evolution, they are presented here because they offer a perspective on the plankton not easily attained through biological studies, based on evidence that can only to be gathered from paleontology. Identification not only of the age of individual living species, but also groups of species with significantly different ages, opens up new possibilities for concentrating molecular genetics studies where they will have more impact. Again, this will require new cooperative research between paleontologists and biologists, first to identify many of the cysts through incubation experiments (e.g. 14 of the 20 species illustrated in Figure 3 are known so far only from the cysts), and then to establish cultures that may be used for genetic and e.g. autecological research.

Another specific topic identified as particularly relevant to future applications of molecular genetics concerns the acritarchs (discussed above). There are many more living acritarchs than the literature suggests, for reasons stated above. The morphology of many acritarchs is simple, but the fossils have been classified into morphological groups, some of which may be traced through long periods of the Paleozoic and Mesozoic Eras, and are represented by living forms today. This suggests possibilities for future studies to target a selection of the morphological groups of living acritarchs. I advocate this approach, not from an assumption that these simple morphological acritarchs have to necessarily represent identifiable genetic links to their ancient Paleozoic look-alikes, but the possibility is interesting enough to merit investigation. These sort of investigations inevitably alter the way in which we view our science, and this in itself has great value: discovering that one proper acritarch was the resting cyst of a thecate dinoflagellate does not imply that all are, but it supports the possibility that at least some could be, in which case finding out which would move the subject forward. The fact that athecate dinoflagellates seem to produce only acritarchous cysts today may prove to be particularly significant. The athecate forms represent a large subdivision today, and yet their fossil record is probably excluded from the currently recognized record of dinoflagellates, since this is based solely on cysts reflecting thecate morphology.

\section{Paleoceanography: the widening credibility gap}

One of the major concentrations of scientific resources, today, is invested in climate-related studies, fueled by public concern over the threat of imminent global warming. The main thrust of the research strategy being followed involves modeling past and present climate, as a basis for assessing possible developing changes for the future. Micropaleontology is largely responsible for feeding the modelers with climatic data from the past, using various groups of microfossils from cored ocean bottom sediments as paleoclimatic indicators, and this is now established as a main field within paleoceanography. Virtually nothing was known regarding the living ecology of the first fossil groups to be applied, e.g. planktic foraminifera, precluding possibilities for developing a direct paleoecological basis for interpreting past water temperatures and salinities.

A statistically-based alternative, the now famous transfer function method (TFM), was devised by Imbrie and Kipp (1971), and this has formed the basis for applications using different microfossil groups ever since. Description of the method and its application is beyond the scope of this discussion, but it relies on a basic assumption that there is a relationship between the distribution of the organisms and the few selected environmental parameters of interest (i.e. temperature and salinity). The method then uses statistical treatments to relate the distribution of microfossils in present day surface sediments to the known values measured from overlying waters (the transfer function). This, in turn, is used to estimate paleotemperatures etc., from the microfossil assemblages, and in this way, massive amounts of plausible data on estimated winter and summer values have been incorporated into the models over the past 25 years. 
Of particular interest, here, is the fact that the transfer function method has also been applied to dinoflagellate cysts (e.g. see de Vernal et al., 1997, and references therein), allowing comparison with the known ecology of cysts referred to above. While the TFM itself is not reliant on ecological interpretations, its scientific value would be increased if ecological credibility could be shown. Comparison between the two, in fact, shows just the opposite: a widening credibility gap.

A fuller discussion of this topic is presented elsewhere (Dale, B. and Dale, A.L., in press), and will not be repeated here. Nevertheless, it may be of interest to plankton biologists to consider the main points of contention. The transfer functions used for cysts are largely based on the same data set of assemblages from surface sediments in the northern North Atlantic, and the following points should be considered: 1) many of these samples are from the deep sea, and almost all of the others from exposed offshore sites - cyst assemblages therefore probably reflect long distance transport, rather than local representation; 2) the assemblages include many well known coastal species seemingly confirming the influence of transport; 3 ) most of the cysts commonly frequent in the assemblages represent species with well documented broad tolerance levels for water and salinity - suggesting no ecological basis for their use to distinguish the relatively small differences estimated from the TFM; 4) if the cysts are presumed to be in situ, as in the TFM, the main conclusion that they somehow reflect environmental parameters (e.g. temperature, salinity, and ice cover) in winter, when presumably they would be dormant, seems particularly unrealistic; and 5) nutrition, and other environmental factors known elsewhere to be more important for determining the composition of cyst assemblages are generally not considered.

We have appealed for a more ecological-based approach to the paleoecological use of cysts and other microfossils, using modern statistical methods (correspondence analysis) developed for terrestrial ecology (Dale, A.L and Dale, B., in press). However, it will probably require a scientific effort corresponding to that already invested in the TFM for such methods to produce similarly detailed data as required by the modelers; if indeed it is realistic to produce such data. In the meantime, micropaleontology will continue to feed in estimates of sea surface temperature and salinity (for February and August) and sea ice cover from records of up to many tens of thousands of years, based on the TFM. This topic is raised, here, because our assessment suggests that, at least for dinoflagellate cysts, the detailed estimates of environmental parameters lack ecological credibility, such that other (as yet unknown) factors must be invoked to explain the established statistical correspondence, if this is to be believed.

Some of our criticism pertains especially to the cysts (e.g.the transport problem, and environmental responses during dormancy). Other groups such as planktic foraminifera, which at least are unquestionably pelagic, may be reliable indicators of the estimated paleo-data produced, but as with the cysts, this should be tested against real ecology if possible. Marine biology could be playing a much more active role in this respect, and future work should be targeted to thoroughly investigate the living ecology of the relevant groups for oceanic micropaleontology (dinoflagellates, diatoms, foraminifera, and radiolaria), and provide input to what otherwise would amount to paleontology in biological limbo.

\section{Environmental sciences}

The developing role of dinoflagellate cysts in environmental sciences (discussed above) certainly raises questions of interest to marine biology. We are well on the way towards developing the cysts as state of the environment indicators with respect to eutrophication, although as yet this is based on relatively few examples. The cyst signals we utilize seem to be both valid (e.g. occurring at different times in the same region, and therefore not climatic) and robust (i.e. both increasing and decreasing in tact with pollution). However, much fundamental work is still needed to understand the underlying biological basis for these signals.

In many ways, the results from the Oslofjord seem straightforward, and at least provide both signals and explanations for these that should be easy to test against future case studies. Using the Oslofjord example as a model for cultural eutrophication in nutrient limited systems suggests two particular implications for future work: the need to test and develop the method, and implications for studies of blooms (discussed in the next section). The cysts in sediments offer a powerful method for tracing the development of cultural eutrophication in nutrient limited systems; the method should now be field tested elsewhere with emphasis on documenting which particular species benefit from the extra nutrients, and therefore contribute to the local signal. The species important in the Oslofjord signal, Gonyaulax polyedra, is a warmer cosmopolitan 
species (equatorial through temperate waters, globally), and therefore a likely candidate also as a summer bloom species elsewhere, at least within the temperate zones. Furthermore, this species also occurs as a prominent member of the plankton in somewhat nutrient enriched neritic waters associated with upwelling systems (e.g. off California, and North West Africa), suggesting the possibility of a more basic link to nutrients than just being a late summer bloomer in the Oslofjord.

The cyst signal for cultural eutrophication in systems not considered to have been nutrient limited prior to human impact is less well understood. The elements of the signal are clear: a proportional shift to more heterotroph representation in the cyst assemblages, with no marked increase in cyst concentration in the sediments. This suggests fundamental changes in the species composition of the plankton, rather than increased overall production, as the main effect of increased nutrients (a point of particular interest for plankton biology). The fact that this signal parallels that previously described for oceanic upwelling, strongly suggests this to be a nutrient signal (Dale, 2000), but the underlying details of which species benefit and which species (or groups of organisms) suffer adverse effects remain to be discovered. The explanation suggested by Thorsen and Dale (1997) and Matsuoka (1999), that extra nutrients produce more diatoms as prey for the heterotrophic dinoflagellates, is not fully supported by the evidence. For the proportional increase noted in the cyst assemblages to represent increased production of heterotrophic dinoflagellates (from increased prey), this should also be reflected by increased production of their cysts (cysts/g sediment), which seems not to be the case. However, much of the evidence so far is complicated by the fact that the sites studied are also subjected to massive industrial pollution, including possibilities for increased sediment loads, and this aspect of the signal should become clearer from ongoing studies of other, less polluted, sites.

Future work should also test the possibilities for using the eutrophication signal quantitatively. The main question to be answered, here, as elsewhere in cyst-based studies, is just how representative is the cyst record of dinoflagellates, or even of the plankton as a whole. On first consideration, the possibilities for quantitative representation seem limited, but it is interesting to note that the approximate doubling of cyst production in the innermost Oslofjord seems to compare reasonably with other indications of eutrophication. Meanwhile, using the signals semi-quantitatively should prove useful for tracing the development of eutrophication. Environmental management decisions could thus be helped by indications of the state of eutrophication relative to preimpact levels, and of suggestions as to whether eutrophication is increasing or decreasing.

Current work using the cyst signals to test suggested links between eutrophication and the collapse of local fisheries (Sætre and Dale, 2001) is providing two converging lines of evidence that could prove to have important implications for both plankton biology and fisheries biology. Eutrophication has been suggested as a possible cause of the collapse of some local fisheries in Norway, involving a postulated deterioration in the quality of food available for early growth stages in the fish. If, as first results suggest, this coincides with cyst signals of eutrophication based on a fundamental shift in species composition of the plankton, these could be pointing to the same changes in plankton also ultimately affecting the fish.

\section{Blooms: the view from below}

There are many areas within the very active field of HAB research where dinoflagellate cysts can provide useful "building blocks" for future work. The most immediate need is for standardized methods for measuring cysts in sediments. Attempts to model bloom dynamics have revealed the need to consider living cysts in bottom sediments as seed beds, and quantify this (numbers of viable cysts hatching to start a bloom). The evidence suggests this to apply to only some HAB species which may be grouped as follows with respect to seed beds (Dale and Amorim, 2000): 1) those lacking resting cysts (e.g. Gymnodinium breve in Florida); those heavily dependent on cysts as seed beds (e.g. Alexandrium tamarensis in higher latitudes); and 3) those producing cysts without mandatory resting periods, and therefore not forming seed beds (e.g. Gymnodinium catenatum from southwestern Europe and northwestern Africa). Attempts to measure viable cysts in sediments will have to take account of a combination of biological and sedimentological factors. It may not be immediately obvious to a biologist or a sedimentologist how a seed bed in rapidly accumulated, coarser grained sediment (with a lower number of cysts/unit of sediment) may be capable of delivering more motile cells/l to overlying waters than a finer grained example with a much higher cyst concentration. 
New toxins and harmful cyst-forming species continue to be discovered, and cysts may be expected to similarly be involved in future discoveries. Two recent examples suggesting future work are of particular interest here: toxins in the cosmopolitan cystforming species Protoceratium reticulatum and $L$. polyedrum (e.g. see references in Reguera et al., 1998), and the new discovery of toxins for the first time within the genus Protoperidinium. The presence of diarrhetic shellfish poison (DSP) toxins in these two cosmopolitan species has several implications for future $\mathrm{HAB}$ research: on the one hand, these produce fossilizable cysts, allowing us to trace the history of past blooms, but also they are dominant members of many cyst assemblages world-wide, in large amounts that could represent sizeable toxin sinks in sediments. The new discovery by Professor T. Yasumoto (personal communication, work in progress) of toxins in a species of Protoperidinium from Ireland is particularly significant: this is one of the largest genera, and may now be expected to contain other toxic species awaiting discovery. From Prof. Yasumoto's description of the motile cells of this species, I was able to recognize a corresponding cyst type from my previous unpublished incubation records; this in turn allows us to seek for this cyst in our global database of recent assemblages, suggesting other localities where this species could cause HAB problem (Dale and Yasumoto, work in progress).

One of the most important areas for future applications of cyst work in HAB (and other bloom) research will involve drawing together some of the various lines of research discussed up to now in this contribution, to explore how these may contribute to better understanding future blooms. This is discussed under its own heading in the following section combining ideas on the future blooms themselves, and the ways they can be studied.

\section{LOOKING BACK INTO THE FUTURE OF BLOOMS AND BLOOMING RESEARCH}

\section{The research}

The harmful component of harmful algal blooms (HABs) refers to effects concerning humans. This means that whereas scientific resources are understandably concentrated on HABs, out of concern for human needs, the scientific need is to better understand plankton blooms as such. Apart from the amount of plankton accumulated to constitute a bloom (or its impact on humans in the case of HABs), one of the main factors unifying most blooms is that they are episodic. Species may bloom at a given site with frequencies varying from almost annually (few) to up to tens of years (scientific records do not allow us to consider more). Episodic phenomena with such frequencies are among the most difficult to study, not least because scientific funding tends to be correspondingly episodic.

Long term monitoring is arguably the most effective (only?) way to build up sufficient data to address the central questions of why and how certain species periodically bloom where and when they do, as shown by the record of HAB research. Within the past 35 years, $\mathrm{HAB}$ research has developed into one of the larger applications of resources in marine biology, fueled by concerns for public health and the commercial interests of fisheries and tourism. The stated primary aims of this research have been to understand, and eventually predict HABs. Looking back over 35 years of research therefore allows us to compare research strategies and to evaluate progress. My personal long term monitoring of research in this field suggests the folowing main conclusions: 1) we still have a lot to learn regarding both understanding and particularly prediction; 2) the most consistent progress has come from research based on long term monitoring, notably in the Seto Inland Sea, Japan, and especially Florida, where records now allow recognition of the combined influence of hydrogrological and meteorological conditions; 3) much other research may be characterized as chasing blooms (i.e. applying often hastily assembled resources to investigate blooms already developing in the field); and 4) experimental work, together with research under 3 above, has however, produced many useful "building blocks".

I believe we would have greater understanding of blooms, today, if more resources had been applied to long term monitoring. Future work should consider the proven value of long term monitoring before dismissing it, perhaps, as unrealistic for the modern world. In any case, it may prove unrealistic to continue along the lines of research covered by points 3 and 4 above, without spending much more collective effort on focussing and integrating the information produced more towards understanding the basic phenomena of blooms. From the literature, and e.g. listening to presentations at the international conferences on HABs held every few years, I sense that bloom research is in danger of losing touch with its own stated goals. Under the general heading of HAB 
research, it is accepted that a wide spectrum of specialist research contributions seem increasingly to dig deeper into their own sub-discipline of science without relating to more than the nearest other one.

The danger is that increased isolation of sub-disciplines within the auspices of a larger topic of public concern ultimately may lead to the sort of credibility gap experienced by the paleoceanographers (discussed above). This point is raised here for consideration by the would-be-sages, as an example of the difficult decisions that have to be made in research, and the longer-term consequences involved. It is not possible to discuss this as fully as it deserves, here, but at least I feel that in mentioning such things, I am to some extent meeting the appeal for "candid, honest and open dialogue" requested by the organizers of this meeting.

However, having appealed so fervently for focussing the detailed sub-disciplines, I should return to integrating the cyst work.

\section{The blooms}

One of the fundamental concerns expressed in $\mathrm{HAB}$ research is that cultural eutrophication may be causing a global epidemic of HABs (Smayda, 1990). One of the goals of future research on blooms therefore must be to investigate the possible effects of eutrophication and other human activities (including climate change). I hope to have shown, here, that some of the main lines of dinoflagellate cyst research in fact cover these same concerns. This allows us to consider implications from the cyst work both for future blooms and for future studies of blooms.

Cyst work described above suggests that cultural eutrophication could cause increased blooms in the future, particularly of summer blooming species in nutrient limited systems of the temperate zones or higher latitudes. The species most affected in the Oslofjord was $G$. polyedra (= L. polyedricum), now known to produce DSP toxins, but other species may be expected to produce similarly increased blooms in other regions. We know insufficient detailed information regarding the effects to be expected on blooms from eutrophication in non nutrient limited systems, but the cysts suggest strong possibility for disruptive changes in plankton composition that could threaten fisheries.

The cyst work relevant to climate change (referred to above) allows us to estimate to some extent the predicted changes to be expected from global warming. Again, the temperate zones and higher latitudes may be expected to be most affected by increased temperature: involving marked increases in the warmer water species occurring towards their colder limits in any given region, today (comparable to the fossil blooms of $G$. nolleri described from previous warmer periods in the Kattegat- Skagerrak). Knowledge of the detailed biogeographic zones mapped out from cyst distribution studies should enable us to identify at least the cystforming species likely to increase. Other kinds of environmental change associated with climate may well affect the warmer zones (e.g. the massive runoff of large amounts of freshwater and mud from large storms in the past few years may represent one of the most disruptive influences on plankton and cysts in sediments along the Portuguese Coast). One of the most pronounced effects of climatic change and various forms of human pollution indicated by the cysts, is an initial spike (from blooms) of $P$. reticulatum. This most likely represents an opportunistic reaction by this cosmopolitan species to environmental change: of particular interest, now, since this species, too, is known to produce DSP toxins.

Cyst analysis of bottom sediments should prove to be a particularly useful method for tracing future changes as they develop. We are already exploring this to trace the joint history of eutrophication (using the eutrophication signal) and toxic blooms of a species, Pyrodinium bahamense, with a fossilizeable cyst (in Manila Bay, The Philippines, in cooperation with Dr. R.V. Azanza).

In our work in Norwegian fjords, we are already picking up the first indicators of the present warming trend, and the results serve as a reminder of the need to observe the details in nature with an open mind: they show a marked increase in the colderwater species $P$. faeroense! Closer examination of the temperature data most likely provides the answer: the consistent measured warming trend in sea surface water temperatures from southern Norway during the past ten years concerns only the winter temperature, summer temperatures are so far not affected. In effect, this allows normal spring temperatures to occur much earlier than otherwise, and extends the spring temperature window by between one and two months. $P$. faeroense is a colder water species occurring towards the warmer limit of its biogeographic zone in these waters, where it blooms in spring. It is thus most likely to have increased its production in the spring bloom during the past ten years, and contributed correspondingly more cysts to the sedimentary record. 


\section{ACKNOWLEDGEMENTS}

Many different sources of funding have helped us carry out this work over many years. Thanks are particularly due the following for financial support: The Office of Naval Research, and The National Science Foundation in the USA (earlier work at Woods Hole Oceanographic Institution); BP International Ltd., U.K., and BP Petroleum Development Norway (initial global cyst study); the AASP-initiated Palynological Research Consortium: Amoco, Norsk Hydro, Phillips, STATOIL, Elf and UNOCAL (a further four years funding for the study); and the Research Council of Norway (current studies on eutrophication and fisheries). I thank: my dear wife Amy for critical reading and help with figures; the personnel of the Graphics and Photography Department of the Mathematics and Natural Sciences Faculty, University of Oslo, for help with illustrations; and Maria L.L. Sætre, Robert W. Williams and Gordon D. Wood, for kindly allowing me to use their photographs in Figure 1.

Finally, I wish to thank Anna Dale and Elise Dale for inspiration that only inquisitive young children can give -I hope that one day this article may help to answer your probing questions about what Pappa really does.

\section{REFERENCES}

Brasier, M.D. - 1980. Microfossils. Allen and Unwin, London.

Dale, B. - 1978. Acritarchous cysts of Peridinium faeroense Paulsen: implications for dinoflagellate systematics. Palynology, 2, 187-193.

Dale, B. - 1983. Dinoflagellate resting cysts: "benthic plankton". In: G.A. Fryxell (ed.), Survival Strategies of the Algae, pp. 69136. Cambridge University Press, Cambridge.

Dale, B. - 1996. Dinoflagellate cyst ecology: modeling and geological applications. In: J. Jansonius and D.G. McGregor (eds.), Palynology: Principles and Applications, pp. 1249-1275. AASP Foundation, Vol. 3.

Dale, B. - 2000. Dinoflagellate cysts as indicators of cultural eutrophication and industrial pollution in coastal sediments. In: R.E. Martin (ed), Environmental Micropaleontology, 305-321. Kluwer Academic/Plenum publishers, New York.

Dale, B. - 2001. Marine dinoflagellate cysts as indicators of eutrophication and industrial pollution: A discussion. Sci. Total Environ., 264: 235-240.

Dale, B. and A. Amorim. - 2000. Dinoflagellate resting cysts as seed beds for harmful algal blooms. Ninth International Conference on Harmful Algal Blooms, Abstract.

Dale A.L. and Dale, B. - (in press). Appendix on statistical methods. In: S. Haslett, (ed.), Quaternary Environmental Micropalaeontology. Arnold Ltd., London.

Dale, B., and A.L. Dale. - (in press). Environmental application of dinoflagellate cysts and acritarchs. In: S. Haslett (ed.), Quater- nary Environmental Micropalaeontology. Arnold Ltd., London.

Dale, B., T.A. Thorsen and A Fjellså. - 1999. Dinoflagellate cysts as indicators of cultural eutrophication in the Oslofjord, Norway. Estuar. Coast. Shelf Sci., 48: 371-382.

Evitt, W.R. - 1963. A discussion and proposals concerning fossil dinoflagellates, hystrichospheres, and acritarchs, I. Proc. Nat. Acad. Sci., 49: 158-164.

Fensome, R.A., F.J.R. Taylor, G. Norris, W.A.S. Sarjeant, D.I. Wharton and G.L. Williams. - 1993. A classification of living and fossil dinoflagellates. Micropaleontology, Special Publication, 7: 1-351.

Hammen, T. Van Der, T.A. Wijmstra and W.H. Zagwijn. - 1971. The floral record of the Late Cenozoic of Europe. In: K.K. Turekian (ed.), The Late Cenozoic Glacial Ages, pp. 391-424. Yale Univeristy Press, New Haven, USA.

Imbrie, J. and N.G. Kipp. - 1971. A new micropaleontologial method for quantitative paleoclimatology: Application to a Late Pleistocene Caribbean core. In: K.K. Turekian (ed.), The Late Cenozoic Glacial Ages, pp. 71-181. Yale University Press, New Haven, USA.

Jannasch, H.W. - 1997. Small is powerful: recollections of a micropbiologist and oceanographer. Ann. Rev. Microbiol., 5.

Matsuoka, K. - 1999. Eutrophication process recorded in dinoflagellate cyst assemblages - a case of Yokohama Port, Tokyo Bay, Japan. Sci. Total Environ., 231: 17-35.

Moldowan, J.M. and N.M. Talyzina. - 1998. Biogeochemical evidence for dinoflagellate ancestors in the early Cambrian. Science, 281: 1168-1170.

Reguera, B., J. Blanco, M.L. Fernández and T. Wyatt (eds). - 1998. Harmful Algae, Xunta de Galicia and Intergovernmental Oceanographic Commission of UNESCO.

Smayda, T. - 1990. Novel and nuisance phytoplankton blooms in the sea: evidence for a global epidemic. In: E.Graneli, B. Sundstrøm, L. Edler and D.A. Anderson (eds), Toxic Marine Phytoplankton, pp. 29-40. Elsevier, New York

Stover, L.E., H. Brinkhuis, S.P. Damassa, L. de Verteuil, R.J. Helby, E. Monteil, A.D. Partridge, A.J. Powell, J.B. Riding, M. Smelror and G.L. Williams - 1996. Mesozoic-Tertiary dinoflagellates, acritarchs and prasinophytes. In: J. Jansonius and D.G. McGregor (eds.), Palynology: Principles and Applications. American Association of Stratigraphic Palynologists Foundation, 2: 641-750.

Sætre, M.L.L., B. Dale, M.I. Abdullah and G.-P. Sætre. - 1997. Dinoflagellate cysts as possible indicators of industrial pollution in a Norwegian fjord. Mar. Environ. Res., 44(2): 167-189.

Sætre, M.L.L. and B. Dale. - 2001. Dinoflagellate cysts in sediment cores as indicators of cultural eutrophication in Norwegian coastal waters. This Meeting, Abstract.

Taylor, F.J.R. (ed). - 1987. The Biology of Dinoflagellates. Botanical Monogr., 21.

Thorsen, T.A. and B. Dale. - 1997. Dinoflagellate cysts as indicators of pollution and past climate in a Norwegian fjord. The Holocene, 7(4): 433-446.

Thorsen, T.A. and B. Dale. - 1998. Climatically influenced distribution of Gymnodinium catenatum during the past 2000 years in coastal sediments of southern Norway. Palaeogeogr. Palaeoclimatol. Palaeoecol., 143: 159-177.

de Vernal, A., A. Rochon, J.-L. Turon and J. Matthiessen. - 1997. Organic-walled dinoflagellate cysts: palynological tracers of sea-surface-water conditions in middle to high latitude marine environments. GEOBIOS 30: 905-920.

Wall, D. and B. Dale. - 1966. "Living fossils" in Western Atlantic plankton. Nature, 211: 1025-1026.

Wall, D. and B. Dale. - 1968. Modern dinoflagellate cysts and evolution of the Peridiniales. Micropaleontology, 14: 265-304.

Wall, D., B. Dale, G.P. Lohmann and W.K. Smith. - 1977. The environmental and climatic distribution of dinoflagellate cysts in Modern marine sediments from regions in the North and South Atlantic Oceans and adjacent seas. Mar. Micropaleontol., 2: 121-200. 